\title{
Tumescent infiltration versus femoral nerve block for skin graft harvest-a prospective randomized study
}

\author{
J. Mathew, S. Varghese, S. Jagadeesh \\ Medical College, Kozhikode, Kerala, India
}

Address for correspondence: Jimmy Mathew, Department of Plastic Surgery, Medical college, Kozhikode, Kerala, India. E-mailanujimy@gmail.com

\begin{abstract}
In this prospective, randomized study, 60 patients requiring a single sheet of graft were randomized into 2 groups. Tumescent infiltration was used for anesthesia in one group and femoral nerve block in the other. The pain during administration of anesthesia, the time required for onset of action, the pain during graft harvest and the failure rates were recorded. Statistical comparison was done using Fischers Exact probability test for the failure rates and Mann Whitney- $U$ test for the other parameters. The pain during administration was significantly higher for tumescent infiltration. The time for onset of action was significantly faster with femoral nerve block. The pain during harvest and the failure rates did not show any significant difference. We conclude that tumescent infiltration is more painful than femoral nerve block but equally effective as anesthesia with no difference in the failure and complication rates.
\end{abstract}

\section{KEY WORDS}

Tumescent, Femoral nerve block, Skin graft

\section{INTRODUCTION}

umescent is an excellent method of giving local anesthesia for skin graft harvesting. ${ }^{1}$ Femoral nerve block is also a method of anesthetizing the antero medial aspect of the thigh. ${ }^{2}$ Both methods are routinely used in our department. The following study is an attempt to scientifically compare both approaches.

\section{PATIENTS AND METHODS}

Sixty consecutive patients between 18 and 60 years of age who required a single sheet of graft for lower limb ulcers between May 2003 and December 2004 were included in the study. Diabetics, patients with leprosy and patients who showed a preference for either of these methods of anesthesia during pre-operative counseling were excluded from the study. Informed consent was obtained from all patients and institutional ethics committee clearance got. The patients were randomly divided into 2 groups of 30 each - one tumescent arm and one nerve block arm. Computer generated random numbers were used for this. No pre operative sedation was used.

Tumescent solution was prepared by adding $1 \mathrm{ml}$ of 1 in 1000 epinephrine, $5 \mathrm{ml}$ of $8.4 \%$ sodium bicarbonate, 1500 IU of hyaluronidase, and $30 \mathrm{ml}$ of $2 \%$ lidocaine to $500 \mathrm{ml}$ of ringer lactate.

In the tumescent arm of the study, the region of graft harvest was marked out in the theatre. The four corners were infiltrated with a $1 \mathrm{ml}$ each of $2 \%$ Lidocaine with a 24 
$\mathrm{G}$ needle. A total of $150 \mathrm{ml}$ of tumescent solution was infiltrated through these sites to the marked out area, using $10 \mathrm{ml}$ syringe and a $24 \mathrm{G}$ spinal needle. The patient was asked to grade the pain during administration on a 0 to 10 point scale with zero indicating no pain and 10 indicating the worst pain imaginable (P1t). The action of the anesthetic was tested using a needle every 30 seconds. The time required for the onset of anesthesia was noted in each case (Tt). Skin graft was harvested using a hand held dermatome. The pain during graft harvest was graded by the patient in a similar manner (P2t). Local infiltration for preparing the ulcer bed was given, if necessary, after both pain scores were recorded.

In the femoral nerve block arm of the study, the femoral artery was palpated $2 \mathrm{~cm}$ below the inguinal ligament. A $24 \mathrm{G}$ needle was inserted just lateral to the artery to elicit paresthesia. Even if paresthesia was not forthcoming, $40 \mathrm{ml}$ of $1 \%$ Lidocaine with adrenaline was injected after piercing the deep fascia. If paresthesia was noted, the drug was given in that region. The pain score was noted during administration (P1f) and the time for onset of anesthesia was recorded (Tf). Graft was harvested from the anesthetized area and the pain score (P2f) during harvest was recorded.

Patients were monitored during surgery by a doctor while the procedures and recording of parameters was done by the junior author. ECG and SpO2 were monitored throughout.

The failure rates were compared using Fischers Exact probability test and the pain scores using Mann-Whitney $\mathrm{U}$ test. The statistics were done using KyPlot software package-Version 2 beta 13 (Yoshioka, 2000).

\section{RESULTS}

In the tumescent arm, 1 patient claimed that the drug did not act, became anxious and had to be heavily sedated. He was excluded from the study. In the nerve block arm, in 4 patients, the block did not act, and tumescent had to be infiltrated. These patients were excluded from the study. The differences in failure rates are not statistically significant $(P>0.05)$.

The pain scores during administration are given in [Table 1]. It is significantly higher for the tumescent $\operatorname{arm}(P<0.05)$.
Table: 1 Pain scores during administration

\begin{tabular}{|c|c|c|}
\hline SI. No & P1t & P1f \\
\hline 1 & 3 & 1 \\
\hline 2 & 4 & 2 \\
\hline 3 & 2 & 1 \\
\hline 4 & 1 & 2 \\
\hline 5 & 1 & 2 \\
\hline 6 & 2 & 3 \\
\hline 7 & 3 & 2 \\
\hline 8 & 4 & 1 \\
\hline 9 & 6 & 1 \\
\hline 10 & 3 & 1 \\
\hline 11 & 2 & 3 \\
\hline 12 & 1 & 1 \\
\hline 13 & 1 & 6 \\
\hline 14 & 3 & 1 \\
\hline 15 & 4 & 1 \\
\hline 16 & 5 & 2 \\
\hline 17 & 3 & 2 \\
\hline 18 & 3 & 1 \\
\hline 19 & 2 & 2 \\
\hline 20 & 2 & 3 \\
\hline 21 & 1 & 1 \\
\hline 22 & 2 & 1 \\
\hline 23 & 4 & 2 \\
\hline 24 & 2 & 1 \\
\hline 25 & 2 & 2 \\
\hline 26 & 3 & 1 \\
\hline 27 & 1 & \\
\hline 28 & 3 & \\
\hline 29 & 1 & \\
\hline Mean \pm SD & $2.58 \pm 1.29$ & $1.76 \pm 1.10$ \\
\hline
\end{tabular}

The time required for onset of action was significantly higher for infiltration $(P<0.05)$. [Table 2].

The pain scores during graft harvest [Table 3] did not show any significant difference between the 2 groups $(P>0.05)$. No complications attributable to the mode of anesthesia were noted in any of the patients.

\section{DISCUSSION}

In this study, administration of tumescent was significantly more painful than the nerve block. Both were equally effective as anesthesia, with no significant difference in failure and complication rates.

Tumescent solution is a very dilute solution of local anesthetic, first described for liposuction. It permits lidocaine doses of $35 \mathrm{mg} / \mathrm{kg}^{3}$. This is routinely used for harvest of skin grafts. ${ }^{1}$ Agarwal in 2004 used tumescent local anesthesia for post burn neck contracture release and skin grafting in 30 patients. ${ }^{4}$ He reported $100 \%$ effectiveness and considered minimal blood loss as a major advantage of this technique. He also noted post-operative analgesia 


\begin{tabular}{|c|c|c|}
\hline SI. No & $T t$ & $T f$ \\
\hline 1 & 6 & 2 \\
\hline 2 & 7.5 & 3.5 \\
\hline 3 & 15.5 & 1 \\
\hline 4 & 16 & 0.5 \\
\hline 5 & 6 & 2 \\
\hline 6 & 7 & 2.5 \\
\hline 7 & 8.5 & 1.5 \\
\hline 8 & 8 & 3 \\
\hline 9 & 9 & 4.5 \\
\hline 10 & 9.5 & 5.5 \\
\hline 11 & 9.5 & 1 \\
\hline 12 & 8 & 2 \\
\hline 13 & 8.5 & 3.5 \\
\hline 14 & 8.5 & 0.5 \\
\hline 15 & 10.5 & 1.5 \\
\hline 16 & 17.5 & 2.5 \\
\hline 17 & 11.5 & 2 \\
\hline 18 & 10 & 3.5 \\
\hline 19 & 11 & 3 \\
\hline 20 & 12.5 & 4.5 \\
\hline 21 & 13 & 0.5 \\
\hline 22 & 13.5 & 1.5 \\
\hline 23 & 5.5 & 1 \\
\hline 24 & 6.5 & 3 \\
\hline 25 & 12 & 2.5 \\
\hline 26 & 11.5 & 1.5 \\
\hline 27 & 17 & \\
\hline 28 & 10.5 & \\
\hline 29 & 5.5 & \\
\hline Mean \pm SD & $10.15 \pm 3.4$ & $2.30 \pm 1.31$ \\
\hline
\end{tabular}

lasting for 18 hours. Bussolin et al in 2003 used tumescent local anesthesia for 30 pediatric burns patients for excision and grafting. ${ }^{5}$ They also noted total effectiveness and observed that 26 out of the 30 patients did not need any analgesics for 24 hours post-operatively. In our study also tumescent was extremely effective as an anesthetic agent. The one patient in whom it failed became very anxious after the injections and we suspect that this led to the complaint of pain awareness. The only disadvantages noted were the multiple painful injections and the delayed onset of action. Unfortunately the post- operative analgesia aspect was not studied, so we cannot comment about it.

Femoral nerve block is a reliable method of anesthetizing the anteromedial aspect of the thigh. It can be used for skin graft harvesting, in addition to a variety of surgeries on the thigh and knee. ${ }^{2}$ Khan et al in 1998 used lateral femoral cutaneous nerve block for skin graft harvest in 52 patients. ${ }^{6}$ They reported that it was effective in all patients. We have used a single injection technique without nerve stimulator for the main trunk of the nerve. ${ }^{7}$ The 4 failures also occurred early in our series, indicating the steeper learning curve when compared to simple infiltration of
To

\begin{tabular}{|c|c|c|}
\hline SI. No & $P 2 t$ & $P 2 f$ \\
\hline 1 & 3 & 1 \\
\hline 2 & 0 & 0 \\
\hline 3 & 0 & 1 \\
\hline 4 & 0 & 1 \\
\hline 5 & 6 & 2 \\
\hline 6 & 0 & 0 \\
\hline 7 & 1 & 0 \\
\hline 8 & 1 & 1 \\
\hline 9 & 0 & 2 \\
\hline 10 & 2 & 0 \\
\hline 11 & 0 & 1 \\
\hline 12 & 1 & 0 \\
\hline 13 & 0 & 2 \\
\hline 14 & 2 & 2 \\
\hline 15 & 2 & 2 \\
\hline 16 & 2 & 0 \\
\hline 17 & 1 & 3 \\
\hline 18 & 0 & 0 \\
\hline 19 & 0 & 1 \\
\hline 20 & 1 & 1 \\
\hline 22 & 4 & 0 \\
\hline 23 & 0 & 4 \\
\hline 24 & 0 & 7 \\
\hline 25 & 2 & 1 \\
\hline 26 & 1 & 0 \\
\hline 27 & 1 & \\
\hline 28 & 1 & \\
\hline 29 & 0 & \\
\hline Mean \pm SD & $1.13 \pm 1.4$ & $1.23 \pm 1.58$ \\
\hline
\end{tabular}

tumescent. The technique was found to be very reliable and relatively easy after some experience, especially if care is taken to elicit paraesthesia prior to injection. In our opinion, a nerve stimulator is not a necessity for this nerve block. It is essential to map out the area of anesthesia prior to harvest as encroaching outside causes severe pain.

Our pain scores were rated on an 11-point numeric rating scale (NRS-11). Points are subjectively given from 0-10 both included depending on the severity. Pain rating is commonly done using a $100 \mathrm{~mm}$ visual analogue scale, 4-catogary verbal rating scale, and NRS- 11 . We chose NRS- 11 because it is easier to apply to a blind folded patient on the operation table after administration of anesthesia, graft harvest etc. The NRS-11 is found to be as sensitive as visual analogue scale for rating pain. ${ }^{6}$

\section{REFERENCES}

1. McGregor IA, McGregor AD. Free skin grafts. In: McGregor AD, editor. Fundamental principles of plastic surgery and their clinical applications. $10^{\text {th }}$ edn. London:Harcourt publishers; 2000. p. 42.

2. Calgary regional health authority [Home page on internet]. Canada:Arraf J;C 2004 [updated 2004 April 14;cited 2005 May 27]. Femoral nerve blocks - Anatomy, technique, considerations, 
applications;[about two screens].Available from:http:// www.calgaryhealthregion.ca/clin/anaesth/Regional/Workshop10/ femoraln.htm

3. Klein JA. Tumescent technique for regional anesthesia permits lidocaine doses of $35 \mathrm{mg} / \mathrm{kg}$ for liposuction. Dermatol surg oncol 1990;16:248-63.

4. Agarwal P. Safe method for release of severe post burn neck contracture under tumescent local anesthesia and ketamine. Indian J Plast surg 2004;37:51-4.

5. Bussolin L, Busoni P, Giorgi L, Crescioli M, Messeri A. Tumescent local anesthesia for the surgical treatment of burns and post burn sequelae in pediatric patients. Anesthesiology 2003;99:1371-5.

6. Khan ML, Hossain MM, Chowdhari AY, Saleh QA, Majid MA. Lateral femoral cutaneous nerve block for split skin grafting. Bangladesh medical research council bulletin 1998;24:32-4.

7. Khoo ST, Brown STK. Femoral nerve block - The anatomical basis for a single injection technique. Anesthesia and Intensive care 1983;11:40-2.

8. Breivik EK, Bjornson GA and Skovlund E. A comparison of pain rating scales by sampling from clinical trial data. Clinical journal of pain. 2000;16:22- 8 . 